\title{
Websites offering information about depression or cognitive behaviour therapy reduced depressive symptoms
}

Christensen H, Griffiths KM, Jorm AF. Delivering interventions for depression by using the internet: randomised controlled trial. BMJ 2004;328:265-8.

\section{Q In community dwelling patients with depression, do websites offering information about depression or cognitive behaviour therapy (CBT) reduce depressive symptoms?}

\section{METHODS}

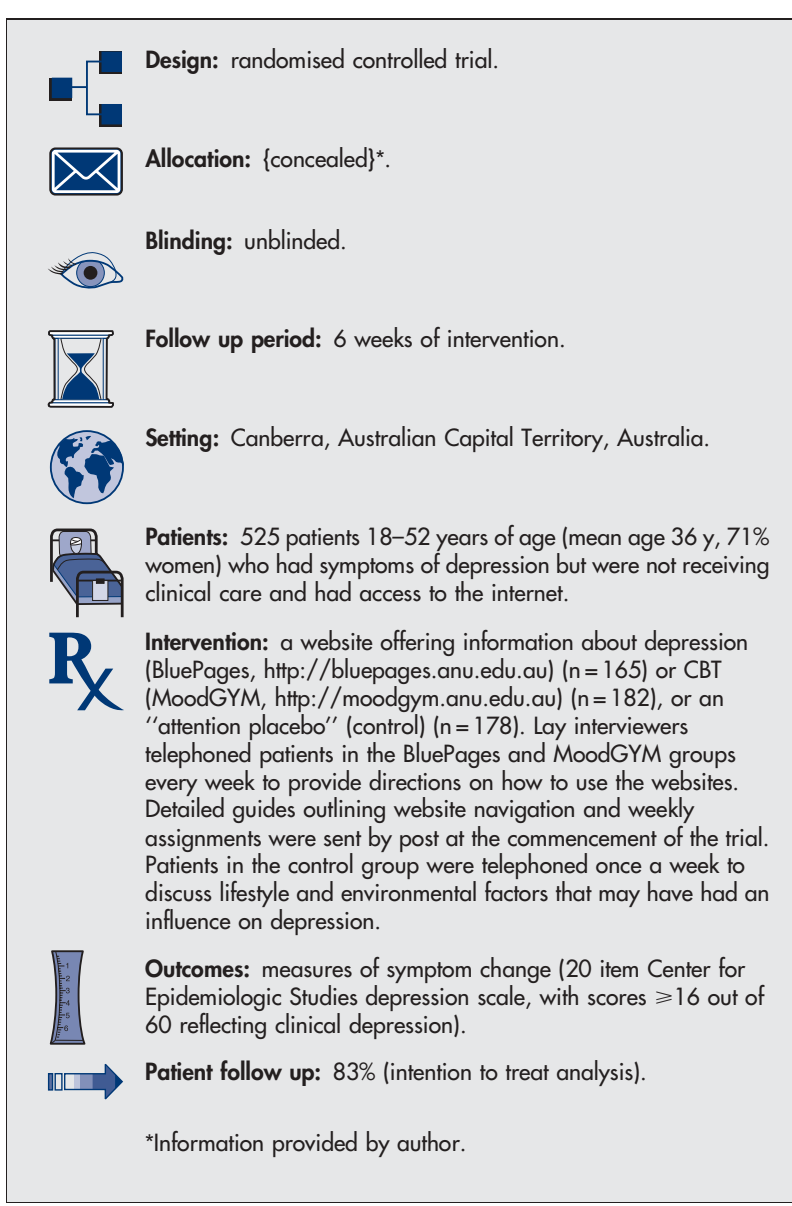

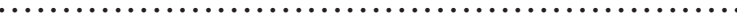
For correspondence: Professor H Christensen, Australian National University, Canberra, Australian Capital Territory, Australia. Helen.Christensen@anu. edu.au

Source of funding: National Health and Medical Research Council Australia.

\section{MAIN RESULTS}

At 6 weeks, reductions in symptoms of depression were greater in both the BluePages and MoodGYM groups than in the control group (table).

\section{CONCLUSION}

In community dwelling patients with depression, websites offering information about depression or cognitive behaviour therapy reduced depressive symptoms.

\section{A modified version of this abstract appears in Evidence-Based Medicine.}

\section{Commentary}

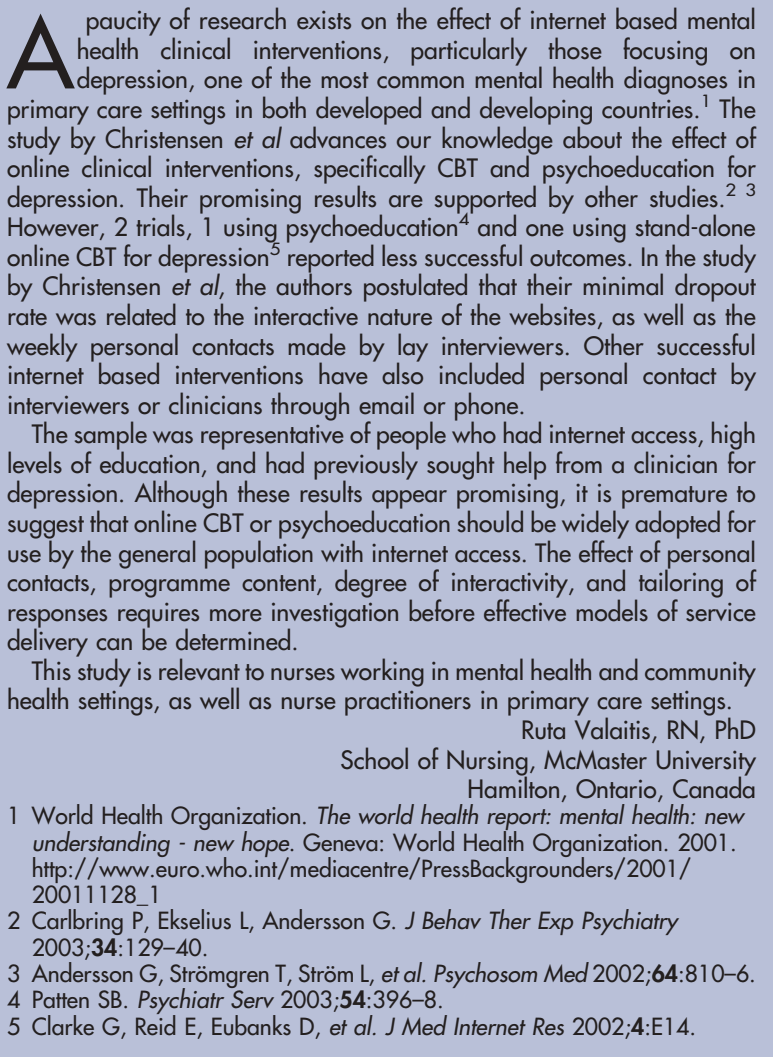

A website offering information about depression (BluePages) or a website offering cognitive behaviour therapy (MoodGYM) $v$ "attention placebo" (control) for depression*

\begin{tabular}{llll}
\hline Outcome at 6 weeks & Comparison & Mean & Difference (95\% Cl) \\
\hline Change from baseline in CES-D† scores & BluePages $v$ control & $3.9 v 1.0$ & $2.9(0.6$ to 5.2$)$ \\
& MoodGYM $v$ control & 4.2 v 1.0 & $3.2(0.9$ to 5.4$)$ \\
\hline
\end{tabular}

${ }^{*} \mathrm{Cl}$ defined in glossary.

†CES-D = Centre for Epidemiologic Studies Depression scale; scores range from 0-60, with scores $\geqslant 16$ reflecting clinical depression. ¥Both significant differences favour BluePages and MoodGYM over control. 